\title{
From Subsidizing for Help to Subsidizing for Education, Improvement of Efficiency of Student Financial Aid Program in Advanced Education
}

\author{
Zhenquan Chen \\ School of Mechanical Engineering \\ Beijing Institute of Technology, Beijing, China \\ e-mail: chenzhenquan1989@126.com
}

\author{
Taipeng Wang \\ School of Mechanical Engineering \\ Beijing Institute of Technology, Beijing, China \\ e-mail: wangtaipeng1985@163.com
}

\begin{abstract}
It is always one of the social spot lights that students whose family have financial difficulties in affording tuition fee of advanced education. University counselors and educational workers need to think carefully about how to raise the efficiency of financial aid program, so that the improvement from subsidizing for help to subsidizing to enlighten could be achieved. Counselors have to ensure the equality of poverty-stricken students and explore the universality of funding sources and directions, so that the basis of funding is solidified and individualized learning can be guaranteed. Therefore, financial aid program is playing an important role in professional education, moral education and quality enhancement, as well as in realizing greater value in education.
\end{abstract}

Keywords-financial aid; poverty identification; helping;education.

\section{FINANCIAL AID OPERATION STATUS OVERVIEW IN} ADVANCED EDUCATION

Along with the deepening of the reform of advanced education and the rapid changing of the society, the trend toward greater influence is obvious. In this process, people are rather concerned about students who have financial difficulties with education. At present, Chinese government has established a financial aid policy system for these students, including national scholarship, national motivational scholarships, national financial aid, national student loans, free normal education, retired soldiers education funding, student loans compensation, workstudy, tuition-fees reduction.[1] In addition, the government encourages social organizations, enterprises and individuals making donations and setting up scholarships and grants, so as to help the admission and consequent learning of students in poverty.[2]

The crucial point in sponsoring students in poverty is to help them with living and studying problem in the education period, hence the name of "helping". On the premise of establishing the financial aid system for students in poverty, the essence of "subsidization to help" is to find the proper recipient groups, judging the degree of the recipients and matching the recipient groups with proper sources. On the basis of solving the "helping" problem, educational workers should figure out how to extend the value of aid sources and how to increase the impact of financial aids in the process of educating people. Effective execution of the student financial aid operations could not only improve efficiency in and of itself, but also makes the linking between management services and personal training more closely, thus achieving the goal of change from subsidization to help to subsidization to educate.

\section{BE PREPARED TO RAISE FINANCIAL AID IN EXTENSIVE WAYS, AND BUILD UP “UNIVERSAL" PLATFORM}

\section{A. The universality of aid sources}

All universities in China have established funding system, but most of the funding system only contains national financial aids, among which the national scholarship, national motivational scholarship and grants are stuck at the level of country. Meanwhile, some universities begin to establish a properly mixed funding system, which is led by the government, and is operated by universities and social group. To enlarge the scope financial aid sources, they need to explore and make the most of social resources due to the limited sources.[3] Nowadays, university students who have financial difficulties are drawing more attention from the enterprises, alumni, charitable organizations, foundations and warmhearted people. Therefore, universities should attract social forces in all means to set up scholarships or assistantships as complements to national scholarship programs. It seems that financial aid program should not only be concerned by department of student work, but multi-departments that could function well under the notion of "education in allinclusive environment". Taking Beijing Institute of Technology (BIT) as an example, by contacting with famous alumni through alumni association, it has established scholarships donated by alumnus, such as "Class 84781 Scholarship" and "Nanjun Tang Scholarship"; BIT has also established "Aerospace Science Scholarship" and "The Northern Industrial Scholarship" in the support of institute of scientific research and enterprises; Based on the researching environment of the department and the association with enterprises, BIT has set up "Beijing Automotive Scholarship" and "Chang' An Scholarship" etc. As a result, $70 \%$ of students in poverty in BIT can be supported simply by the financial aid program.

We have conducted an investigation on the source of living expenses for the undergraduate in the department of mechanical engineering in BIT. In a reducing proportion, the sources are family supplement, undergraduate student aid, scholarship, student loans, work-study activity and lending from each other. The monthly living expenses of 
$800-1500 \mathrm{RMB}$ takes the largest proportion with about $48.3 \%$, and those with less than 800RMB takes about $26.6 \%$, and the rest are over $1500 \mathrm{RMB}$ per month. Currently, the national student aid, together with scholarship and grants and student loans are basically meeting the requirement of students' daily lives.

\section{B. Universality of financial aid directions}

Nowadays, universities have set up goals for cultivation in the direction of "knowledge comprehensive aptitude". Knowledge refers to the education in morality and academics, which is the common goal of talent training; comprehensive aptitude refers to abilities required in moral culture, major skills, research innovation, practical ability and the international field of vision, including not only specialty knowledge and skills, but also the abilities to adapt, learn, innovate and self-develop in new environments. This training can improve students' social adaptability and social competitiveness. Diversified demand for the cultivation program has promote the establishment of the platforms for education, among which the one for "universality" is an important part.

Based on the talent training of the department of mechanical engineering of BIT, the teaching group is cultivated by people with diversified skills and capacity. With the motivation mechanism of individualized learning and advanced career planning management, the school has built up firm foundation for the comprehensive education of undergraduate students. Moreover, they established personal training motivation mechanism of the basic comprehensive quality by actively absorbing and integrating social forces to intensify the "universality" financial aid system based on the concept of quality. The school has set up Rambler Scholarship to encourage devotional spirit, Horiba Scholarship to encourage experiments on vehicle projects, LMS Scholarship to encourage simulation analysis, Li Jiang Scholarship to encourage learning defense knowledge, Fastre Scholarship to encourage students in poverty, Beijing Automotive Scholarship and Chang' An Automotive Scholarship to encourage development of formula cars, and DAEYANG Scholarship to encourage collective culture construction, etc... These scholarships create more room for engineering students to increase their personal competitiveness and personal comprehensive capacities.

\section{2.3 The meaning of "universality" platform}

The construction of "universality" platform is significant to financial aid program. Firstly, the financial aid program is no longer limited in national subsidization, and standards on categorizing aid groups have become diversified, which is not only based on academic scores. With the rapid development of social economy and cultural prosperity, students whose family have financial difficulties should increase requirements from the basic "studying and living" needs to a higher level of demand of "growing-up and individuality".

With the rapid development of society, the poverty level is declining, while the financial aid for poverty- stricken student is gradually increasing.[4] In addition, the proportionality of poverty-stricken students of the grade 2011-2013 is gradually declining.

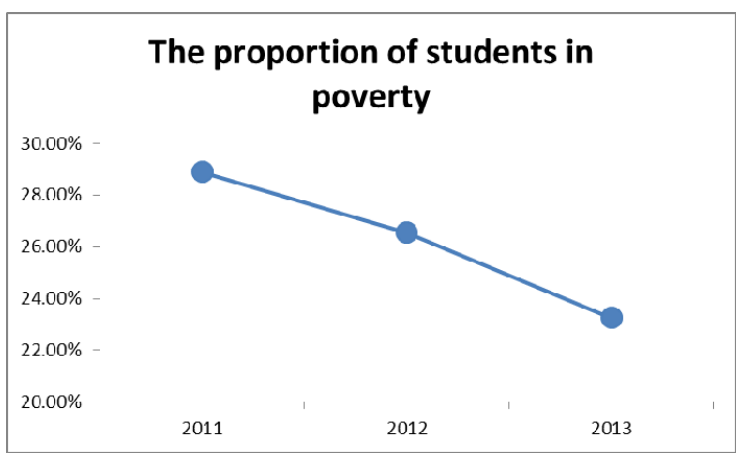

Figure 1 The proportion of students in poverty

By analyzing the recent three-year data of the freshmen of the School of Mechanical Engineering, we find that $30 \%$ of the students are in poverty. $14 \%$ of the students have living expenses more than enough, and $56 \%$ have living expenses basically enough. Among students in poverty, the annual income per family member of less than 10,000RMB takes merely $18 \%$. As a result, the family income is able to meet the low level of living and studying expenses. In conclusion, scholarship and financial aid are not only the source of living expenses, but also the way providing students with opportunities and success.

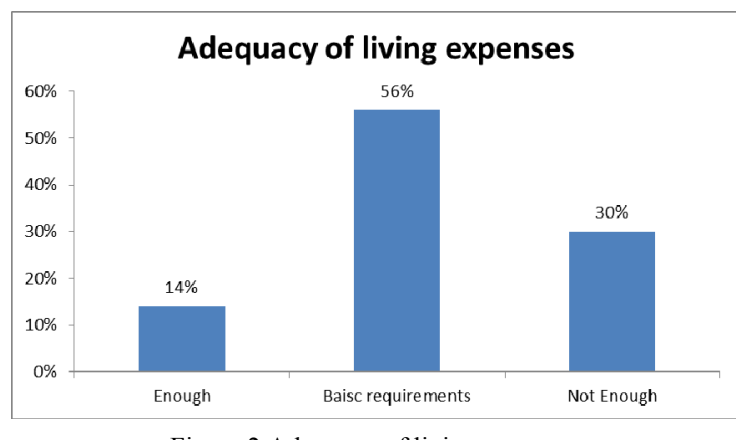

Figure 2 Adequacy of living expenses

The "universality" aid platform provides individualized quality education according to students' characteristics, which provides students in poverty with more opportunities to develop personality, thus promoting education equality on a higher level. Secondly, other functional departments such as alumni, research work are able to focus more on the key point. The program extends from single piece of work in the labor department to mutual cooperation of each department in the university, combining advantages of each part. The corporation has help form a "Cultivation throughout the whole university as a whole" configuration. Therefore, more social sources could be drawn into the education field. 


\section{UNDERSTANDING THE CONNOTATION BEHIND "SUBSIDIZING FOR HELP” AND IMPROVING IT TO "SUBSIDIZING FOR EDUCATION"}

\section{A. From "subsidizing for help" to "subsidizing for education"}

The work of sponsoring students in advanced education is a "Benefaction to People" Project in order to subsidize the students in poverty for education, helping them to matriculate successfully and to finish their studies. In addition, a complete, benign sponsor system can lead students' growing up and success.

For students in poverty, the basic goal of subsidizing is to relieve their poverty, but on a higher level, the value is to educate intellectually in terms of subsiding. That is to cultivate the students to attain the spirit of self-reliance and hard work and to gain awareness of the importance of paying back to the society and the country.[5] Like inducing the subsidized students to regard and treat sponsor correctly and reasonably and to utilize the sponsor to repay the society, etc. To all students in advanced education, sponsoring work can arouse them to realize the attention of education paid by the country and the society and to feel proud of their country and ethics. At the same time, the subsided students are required to participate in the volunteering work in the sponsor system, so that the students can receive education to learn the awareness of responsibility and offering to pay back to the society. To the whole society, more and more students can receive the opportunity to get advanced education. At the same time, they can contribute enormously as human force resources to our country.

\section{B. Some points of "subsidizing for education"}

To different objects in "subsidizing for education" work, we can consider them in several aspects below. In the aspect of subsidized students, we should strengthen the investigation after sponsor and enlighten them to use the sponsor correctly and reasonably. For instance, the obtainer of "Rambler Scholarship" whose culture is to inspire the students who devote themselves to serve their classmates and class without caring about the fame or benefit. Like the classes obtaining "DAEYANG Scholarship" use the sponsor to strengthen the construction of class culture and hold arresting activities, which increase the enthusiasm of students to participate in the class activities and improve the cohesion of the class. Like the formula car team obtaining "Beijing Automotive" use the sponsor partly to provide free yard, equipment and facilities to help students finishing their science innovation work and improve the students' enthusiasm of scientific research and operational ability. In the aspect of all students, by utilizing and creating several kinds of propaganda like making an open reply in public, voting on the internet, speeches of award-winning experience, awards ceremony and so on to offer the subsidized students opportunities to express their pleasure of success and lessons of failure. This will lead more students to supervise and emulate the award obtainer. Also, it will make students to pay attention and participate in subsidizing work, which is meaningful to the construction of campus culture. In the aspect of the entire society, colleges and universities should seek supports from companies. Different social resources have its own characteristic and different companies value the talent in different ways. We can establish different scholarship and subsidizing award related to characteristic of different social resources like the scholarship focusing on sports, art activities, software simulation and scientific research. By utilizing several media tools to broadcast subsidizing work, more and more social resources are made to support education career in order to establish the connection between the subsidizing work and personal training work and the connection between the scholarship work and the service of vocational counseling work.

\section{The FEEDBACK OF PRACTICAL EFFECT}

To analyze the work efficiency of financial aid program making changes from "subsidizing for help" to , we take a sample from undergraduate students of School of Mechanical Engineering, Beijing Institute of Technology (total amount of approximately 1000 participants from third and fourth year students), and collect data and calculate percentages from this participants. The statistical results show that $75 \%$ of students in poverty received financial aids as diversified individualized grants, and the proportion goes up to approximately $100 \%$ if forms of student loans and workstudy type are taken into account. In the index of participants who won the honorary title in university-level or above, the proportion of students in poverty is $25 \%$, slightly higher than overall average proportion which is $23 \%$. In the index of participants who won science and technology innovation award in university-level or above, the proportion of students in poverty is $18 \%$, higher than overall average proportion which is $13 \%$. From academic indicators, the proportion of students in poverty who have failed subjects is $19 \%$, lower than average level which is $23 \%$. The proportion of students in poverty whose degree qualification would be canceled is $2 \%$, below the average level of $3 \%$. As for the diathesis indexes, the proportion of students in poverty who won sports and arts awards in university-level or above is consistent with the average level, which is $10 \%$ and $5 \%$ respectively. It can be concluded that students in poverty participate in cultural activities and sports activities as frequent as regular students, but they participate more in other activities. Therefore, the establishment of "universal" financial aid platform plays an important role in the improvement of financial aid work efficiency and directions of personnel training.

The subsiding work in the universities and colleges is one of the most serious issues in student groups. The guidance and education characteristic are self-evident. With the rapid development of social economy, the requirements of the human resource from the society change, which indicate that our staff in universities should follow the social features, explore different approaches, 
improve the effectiveness of subsidizing and create new prospects from "subsidizing for help" to "subsidizing for education".

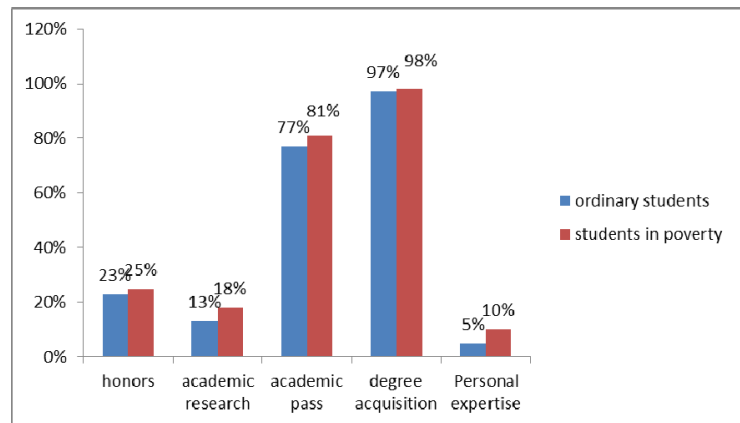

Figure 3 Data discrepancies between ordinary students and students in poverty

\section{REFERENCE}

[1] Zhang Yue, "Related thinking about how to identify poor college students' work," in Culture, Vol. pp. 187-188, November 2008.

[2] Lan Yuanhui,"Psychological Analysis of Poor College Students and Countermeasures of government management" in JINAN University (Philosophy and Social Sciences), Vol. 32, March 2010.

[3] Yin Juan, "Universities Research Grants established comprehensive evaluation," in University Education, pp. 107-108, May 2012.

[4] $\mathrm{Hu}$ Liwei, "Grants and financial aid of college students under education fair system," in Chinese Medical Ethics, Vol.23 pp. 102-103, March 2010.

[5] Yu Jiachao, "The research between college work-study and Undergraduate employability", in Chinese Geological Education, pp. 9-13, March 2010 . 